\title{
Review Article \\ Urinary Biomarkers in the Assessment of Early Diabetic Nephropathy
}

\author{
Cristina Gluhovschi, ${ }^{1}$ Gheorghe Gluhovschi, ${ }^{2}$ Ligia Petrica, ${ }^{1}$ Romulus Timar, ${ }^{3}$ \\ Silvia Velciov, ${ }^{1}$ Ioana Ionita, ${ }^{4}$ Adriana Kaycsa, ${ }^{5}$ and Bogdan Timar ${ }^{3}$ \\ ${ }^{1}$ Division of Nephrology, University of Medicine and Pharmacy "V. Babes", 300041 Timisoara, Romania \\ ${ }^{2}$ Romanian Academy of Medical Sciences, 300041 Timisoara, Romania \\ ${ }^{3}$ Department of Diabetes and Metabolic Diseases, University of Medicine and Pharmacy "V. Babes", 300041 Timisoara, Romania \\ ${ }^{4}$ Division of Hematology, University of Medicine and Pharmacy "V. Babes", 300041 Timisoara, Romania \\ ${ }^{5}$ Department of Biochemistry, University of Medicine and Pharmacy "V. Babes", 300041 Timisoara, Romania
}

Correspondence should be addressed to Cristina Gluhovschi; gluhovschi@yahoo.com

Received 24 March 2016; Accepted 12 May 2016

Academic Editor: Nikolaos Papanas

Copyright (C) 2016 Cristina Gluhovschi et al. This is an open access article distributed under the Creative Commons Attribution License, which permits unrestricted use, distribution, and reproduction in any medium, provided the original work is properly cited.

Diabetic nephropathy (DN) is a frequent and severe complication of diabetes mellitus (DM). Its diagnosis in incipient stages may allow prompt interventions and an improved prognosis. Towards this aim, biomarkers for detecting early DN can be used. Microalbuminuria has been proven a remarkably useful biomarker, being used for diagnosis of DN, for assessing its associated condition-mainly cardiovascular ones-and for monitoring its progression. New researches are pointing that some of these biomarkers (i.e., glomerular, tubular, inflammation markers, and biomarkers of oxidative stress) precede albuminuria in some patients. However, their usefulness is widely debated in the literature and has not yet led to the validation of a new "gold standard" biomarker for the early diagnosis of DN. Currently, microalbuminuria is an important biomarker for both glomerular and tubular injury. Other glomerular biomarkers (transferrin and ceruloplasmin) are under evaluation. Tubular biomarkers in DN seem to be of a paramount importance in the early diagnosis of DN since tubular lesions occur early. Additionally, biomarkers of inflammation, oxidative stress, podocyte biomarkers, and vascular biomarkers have been employed for assessing early DN. The purpose of this review is to provide an overview of the current biomarkers used for the diagnosis of early DN.

\section{Introduction}

Diabetic nephropathy (DN) represents an important cause of chronic kidney disease (CKD) that frequently leads to end stage renal disease (ESRD). Diabetes mellitus (DM) is a frequent disease and $\mathrm{DN}$ is one of its main complications. It is appreciated that up to $40 \%$ of the patients with type I and type II DM present DN [1]. In Western countries, diabetes is a leading cause of chronic kidney disease frequently leading to chronic renal replacement therapy (RRT) due to ESRD [2].

Taking into account the increased incidence of both DM and of DN, the detection of early DN is of paramount importance, in order to provide appropriate therapy that prevents or slows evolution towards ESRD.
Biomarkers play an important role in the early detection of DN. Among them, the best known is microalbuminuria. At the same time, microalbuminuria represents a marker of the generalized endothelial dysfunction present in DM, linking renal involvement with cardiovascular and cerebral impairment.

In time, it has been demonstrated that microalbuminuria reflects not only glomerular injury but also tubular lesions, filtered albumin being reabsorbed at tubular level. Additionally, new biomarkers have been studied in order to identify tubular lesions in DM.

The new tubular biomarkers have been detected in both type 1 and type 2 DM early renal dysfunction that precedes microalbuminuria. At present, the assessment of early DN 
involves numerous biomarkers. They span the period of normoalbuminuria that precedes microalbuminuria but also the evolution of renal involvement during microalbuminuria and macroalbuminuria.

Until they are universally accepted they are analyzed in relationship with the levels of albuminuria, especially of microalbuminuria.

At present, markers of inflammatory and oxidative processes accompanying DM and DN are also being assessed.

Since literature abounds in studies on markers highlighting renal dysfunction in different stages of the evolution of DM, we decided to restrict our study to the early phase of DN.

An update of the urinary biomarkers used in early DN is useful for establishing their role in the early diagnosis of this disease, with subsequent prophylactic and therapeutic implications. We insist on urinary biomarkers because they are easily drawn, which allows population screening, and because they can detect tubular lesions, which occur very early in DM.

Proteomics is an additional tool offering great prospects in DN assessment.

The origin of the biomarkers employed for assessing renal involvement in DM is diverse. Some of the biomarkers are constitutive elements of the nephron, such as markers at

(i) epithelial cell (podocyte) level, for example, nephrine and podocalyxin [3];

(ii) glomerular basement membrane level: collagen and laminin [4];

(iii) endothelial (VEGF) [5];

(iv) tubular cell level, for example, NGAL, NAG, and KIM [6].

Some have mixed origin; they can originate both in tubular cells and in podocytes, for example, angiotensinogen $[7,8]$.

Some are derived from the circulation, for example, transferrin, ceruloplasmin, and immunoglobulins G and M. They pass into the urine because of glomerular lesions which result in increased permeability for plasma proteins.

There are several classifications addressing the diversity of urinary biomarkers in DM.

Matheson classifies the biomarkers according to both their origin and the pathologic processes impairing the nephron: kidney damage, oxidative stress, and inflammation:

(i) biomarkers of renal dysfunction,

(ii) inflammatory biomarkers (cytokines and chemokines),

(iii) oxidative stress biomarkers [9].

Another classification belongs to Hong and Chia who present 3 categories of biomarkers:

(i) glomerular,

(ii) tubular,

(iii) other proteins [10].
It should be noted that products of metabolism in DM are also eliminated in the urine, and they can trigger toxic effects, for example, advanced glycation end products (AGE).

Since we will frequently refer to microalbuminuria in presenting other biomarkers used in studying lesions of the nephron, namely, of the glomerulus and of the tubules, we will first present the main observations regarding microalbuminuria in diagnosing $\mathrm{DN}$.

Recent literature uses new terms, like moderately increased albuminuria for microalbuminuria and severely increased albuminuria for macroalbuminuria. However, the classical terms of microalbuminuria and microalbuminuria continue to be in wide use, as they are more practical. This is why we will prefer them in the present paper.

Urinary biomarkers use in assessment of early diabetic nephropathy are presented in Table 1 .

\section{Microalbuminuria (Moderately Increased Albuminuria) in Type 1 DM}

Microalbuminuria usually begins 5-10 years after the onset of type 1 DM [11].

Kidney biopsy examination in patients with type $1 \mathrm{DM}$ and microalbuminuria most frequently finds normal histological aspects. However, DN lesions were found in a small number of patients [12].

According to McKenna and Thompson, microalbuminuria is predictive element of the future development of end stage renal disease [13].

Microalbuminuria can regress towards normoalbuminuria, it can persist as such, or it can progress towards albuminuria $[14,15]$.

The evolution of microalbuminuria towards macroalbuminuria is usually related to arterial hypertension and reduced GFR, an important part being generally played by risk factors [16].

Persistent microalbuminuria is related to future development of end stage renal disease and to cardiovascular risk [13].

It should be noted that diminution of GFR usually occurs after the development of microalbuminuria, but there are situations when even normoalbuminuria is accompanied by diminution of the GFR [17].

\section{Microalbuminuria (Moderately Increased Albuminuria) in Type 2 DM}

Microalbuminuria is an important biomarker in type 2 DM, being frequently used in population-based screenings.

Regarding the prevalence of microalbuminuria in type 2 DM patients we highlight a review of Newman et al. of 28 studies on 10,294 patients. They found microalbuminuria in $26 \%$ of the patients with ten-year duration of the disease [18].

A study on 24,000 patients found that Asian and Hispanic patients with type $2 \mathrm{DM}$ present more often microalbuminuria (43\%) than whites (33\%) [19].

In China, Shanghai, microalbuminuria has a prevalence of $41 \%$ among patients with type 2 DM [20].

Hypertensive patients with type 2 DM present microalbuminuria more frequently [21]. 
TABLE 1: Urinary biomarkers in the assessment of early diabetic nephropathy.

\begin{tabular}{|c|c|c|}
\hline Glomerular biomarkers & & Tubular biomarkers \\
\hline Transferrin & \multirow{10}{*}{$\begin{array}{l}\text { Microalbuminuria } \\
\text { The main marker in current use }\end{array}$} & Neutrophil gelatinase-associated lipocalin (NGAL) \\
\hline Immunoglobulin $\mathrm{G}$ & & Alpha-1-microglobulin \\
\hline Ceruloplasmin & & Kidney injury molecule-1 (KIM-1) \\
\hline Type IV collagen & & $\mathrm{N}$-acetyl- $\beta$-D glucosaminidase \\
\hline Laminin & & Angiotensinogen \\
\hline Glycosaminoglycans & & Cystatin C \\
\hline Lipocalin-type prostaglandin D synthase & & Liver-type fatty acid binding protein \\
\hline Fibronectin & & Nephrine \\
\hline Podocytes-podocalyxin & & Heart fatty binding protein \\
\hline Vascular endothelial growth factor/VEGF & & Advanced glycation end products \\
\hline Inflammatory biomarkers & Other new markers under study & Oxidative stress biomarkers \\
\hline Tumor necrosis factor alpha & Retinol binding protein- 4 & 8-Oxo-7,8-dihydro-2'-deoxyguanosine \\
\hline \multirow[t]{7}{*}{ Orosomucoid } & Vitamin $\mathrm{D}$ binding protein & \\
\hline & Heme oxygenase-1 & \\
\hline & Periostin & \\
\hline & Alpha klotho & \\
\hline & $\begin{array}{l}\text { Microvesicle-bound dipeptidyl } \\
\text { peptidase IV }\end{array}$ & \\
\hline & MicroRNA & \\
\hline & $\begin{array}{l}\text { Adipokinesine alpha-2 } \\
\text { glycoprotein }\end{array}$ & \\
\hline
\end{tabular}

Microalbuminuria can have a variable evolution. It can regress towards normal values, it can progress towards macroalbuminuria, or it can remain unchanged. In a study on 216 patients, Araki et al. found, after a 6-year follow-up, regression of microalbuminuria in $51 \%$ cases and progression to severely increased albuminuria in $28 \%$ cases [22].

The risk of progression to severely increased albuminuria is higher in patients with microalbuminuria as compared to patients with normoalbuminuria [18].

The diminution of GFR is also higher in patients with severely increased albuminuria than in those with microalbuminuria [23].

Glycemic control, ACE inhibitors, and ARBs for blood pressure control play an important role in the evolution of microalbuminuria. It should be mentioned that microalbuminuria has been considered a glomerular biomarker. To date, emerging data point to the role of the tubules in producing microalbuminuria $[24,25]$. As such we did not include this marker among glomerular biomarkers but approached it separately, according to its potential role as both a glomerular and tubular biomarker.

\subsection{Glomerular Biomarkers}

3.1.1. Urinary Transferrin. Transferrin is a protein with a molecular weight of $76.5 \mathrm{KDa}$. Because of its low molecular weight and its less ionic load it filters easily through the glomerular barrier [26].

As increased urinary transferrin was found in type 2 DM normoalbuminuric patients, concomitantly with urinary ceruloplasmin and immunoglobulin G, preceding microalbuminuria, it could be considered a biomarker of early DN [27].

In microalbuminuric patients the levels of urinary transferrin increase [28]. They also increase in patients with type 2 DM with vascular complications: coronary artery disease, diabetic retinopathy, and so forth [29].

Patients with initial high levels of urinary transferrin excretion will develop microalbuminuria more frequently than those with normal levels [30].

3.1.2. Urinary Immunoglobulin $G$. It is an anionic plasma protein with a molecular weight of $150 \mathrm{KDa}$ that crosses the glomerular barrier with difficulty [31].

As presented above, urinary IgG can be secreted before the stage of microalbuminuria, concomitantly with increased values of urinary transferrin, urinary ceruloplasmin, and urinary orosomucoid [27].

Increased elimination of urinary IgG could thus predict microalbuminuria in DM patients [27].

3.1.3. Urinary Ceruloplasmin. Ceruloplasmin is a coppertransporting serum protein. It is filtered with difficulty at glomerular level because it is more negatively charged [32].

It was also found in some type $2 \mathrm{DM}$ patients with normoalbuminuria, arguing in favour of its use for early detection of renal lesions, even prior to albuminuria: ceruloplasmin could have in type $2 \mathrm{DM}$ patients a DN predictive effect, similar to urinary transferrin and urinary immunoglobulin G [27]. According to Yamazaki et al. the 
urinary ceruloplasmin excretion rate (CER) and clearance of ceruloplasmin increase in parallel with the progression of albuminuria [33].

In fact, in type $2 \mathrm{DM}$ patients there could exist a parallelism between increased values of urinary transferrin, urinary immunoglobulin G, and urinary ceruloplasmin [27].

We conclude that urinary ceruloplasmin could be used for the early diagnosis of DN [34].

3.1.4. Type IV Urinary Collagen. Type IV collagen is a component of the glomerular basement membrane and of the mesangial matrix [35].

In $\mathrm{DN}$, lesions are produced both at glomerular capillary level and at mesangial level. Its excretion in urine might serve as early indicator of renal injury associated with DN [36].

Increased levels of type IV urinary collagen are reported for normoalbuminuric patients with type $1 \mathrm{DM}$. It could be a biomarker used for the early diagnosis of DN [37]. Other authors also report increased excretion of type IV collagen and of laminin in patients with type 1 DM [23].

High urinary type IV collagen excretion was also reported in normoalbuminuric patients with impaired glucose tolerance [38].

Urinary type IV collagen could reflect morphological renal alterations in patients with type $2 \mathrm{DM}$. A relationship between the severity of histological lesions and urinary type IV collagen was reported in patients with type 2 DM [39].

Type IV urinary collagen is considered to be a specific indicator of early DN [40].

It could also allow both detection of early $\mathrm{DN}$ in patients with type $2 \mathrm{DM}$ and differential diagnosis with glomerulonephritis, where its levels are low [41].

3.1.5. Urinary Laminin. Laminin is a component of the glomerular basement membrane. Its urinary excretion is increased in normoalbuminuric type $2 \mathrm{DM}$ patients, being correlated with NAG (N-acetyl-beta-D-glucosaminidase) and alpha-1-microglobulin excretion. Concomitantly increased excretion of type IV collagen is found [4].

3.1.6. Urinary Glycosaminoglycans. Glycosaminoglycans are components of the glomerular basement membrane as well as of the extracellular matrix. In DM alterations of these occur, the excretion of glycosaminoglycans being increased, even in normoalbuminuric patients [42].

Glycosaminoglycans are also present at the level of the tubular basement membrane. Urinary glycosaminoglycans are associated with other tubular biomarkers, for example, Tamm-Horsfall protein, which expresses a distal tubular dysfunction in diabetic patients [43].

3.1.7. Lipocalin-Type Prostaglandin-D Synthase (L-PGDS). It is a biomarker related to lesions of the glomerular capillary walls and reflects their increased permeability. It is mainly considered to predict renal lesions, being less relevant as an early marker of DN [44].
3.1.8. Urinary $\operatorname{Ig} M$ and Urinary Fibronectin. These were studied only sporadically, without sufficient data to support their use as markers of early DN.

Urinary fibronectin excretion is significantly increased in DM patients only if they present microalbuminuria [45]. IgM is an indicator of impaired kidney function [46].

Although the use of urinary glomerular biomarkers has not become current practice yet, glomerular biomarkers have been reported in some normoalbuminuric patients, leading to the conclusion that albuminuria might not represent the most sensitive glomerular biomarker. However, their clinical applicability needs to be confirmed in high-quality validation studies [31].

3.2. Tubular Biomarkers. DN is manifested mainly by wellknown glomerular lesions. The aforementioned biomarkers are identified already precociously early in early DN. Tubulointerstitial lesions are associated with glomerular injury during DN [47]. Tubular biomarkers have shown that tubular dysfunction can be present early in $\mathrm{DN}$, sometimes preceding glomerular injury. These biomarkers have proven highly sensitive as compared to microalbuminuria, which is considered the gold standard biomarker of DN. In fact, presently, microalbuminuria is regarded not only as a glomerular biomarker, but also as a tubular one.

3.2.1. Neutrophil Gelatinase-Associated Lipocalin (NGAL). NGAL - neutrophil gelatinase-associated lipocalin-is a glycoprotein present in the kidneys at tubular cell level and is considered to be protective against renal damage [48].

Urinary NGAL is a biomarker used in assessing tubular lesions in DM, its increased values being present even in the initial phases of the disease, namely, in normoalbuminuric patients [49].

Thus, in type $1 \mathrm{DM}$ high urinary NGAL can precede microalbuminuria $[50,51]$.

Urinary NGAL had high values in type $2 \mathrm{DM}$ patients with normoalbuminuria, increasing progressively in patients with microalbuminuria and macroalbuminuria. The values of KIM-1 (kidney injury molecule-1) increased in parallel, indicating an early and progressive lesion [52].

However, $\mathrm{Fu}$ et al. reported in type $2 \mathrm{DM}$ patients who present hyperfiltration and increased values of urinary NGAL, as well as of urinary KIM-1, as compared to the values of patients with normal GFR [53].

Urinary NGAL shows the precocity of tubular lesions in patients with prediabetes [54].

Urinary NGAL in type $2 \mathrm{DM}$ patients could have a role in predicting the evolution of disease [55].

3.2.2. Urinary Alpha-1-Microglobulin. Urinary alpha-1microglobulin is a serum protein with low molecular weight $(27-\mathrm{kDa})$, which allows it to get easily filtered through the glomerular capillary wall. Once it arrives in the proximal tubule, alpha-1-microglobulin is reabsorbed and metabolized. Tubular dysfunction leads to alteration of reabsorption with increased excretion in the urine [56].

In a cross-sectional study, Hong et al. analyzed 590 type $2 \mathrm{DM}$ patients and found that $33.6 \%$ patients with 
normoalbuminuria presented increased values of urinary alpha-1-microglobulin, a fact that could be explained by tubular injury that precedes the occurrence of microalbuminuria, being a more sensitive and an earlier urinary biomarker [57]. However, alpha-1-microalbuminuria can be absent in some patients with albuminuria [57]. This is why assessments of alpha-1-microglobulin are associated with the assessment of other urinary biomarkers, urinary albumin included.

Petrica et al. reported high values of urinary alpha-1microglobulin in normoalbuminuric patients, a fact pleading for an early tubular injury in type $2 \mathrm{DM}$ in this stage. They did not find correlations between urinary alpha-1-microglobulin, beta- 2 microglobulin, and the albumin/creatinine ratio with plasma asymmetric dimethyl-arginine. This could plead for dissociation between tubular and endothelial dysfunction [58].

Alpha-1-microglobulin in early stages of DM could also have a role in predicting DN [59]. It is in fact an inexpensive biomarker of early diagnosis of DN [60].

3.2.3. Urinary KIM-1 (Kidney Injury Molecule-1). KIM-1 is a transmembrane glycoprotein located at the level of the proximal tubular cells. It is eliminated in urine in case of injury at this level. It is a sensitive biomarker used with good results in acute kidney injury [61].

Petrica et al. reported in normoalbuminuric type $2 \mathrm{DM}$ patients high values of urinary KIM-1, which indicates lesions of the proximal tubule in early stages of the disease. Patients with microalbuminuria have higher urinary KIM-1 values than those with normoalbuminuria [62].

de Carvalho et al. reported in type 2 DM normoalbuminuric patients high values of KIM-1, these values increasing progressively in patients with microalbuminuria and macroalbuminuria. NGAL values studied concomitantly presented similar evolutions [52].

Moreover, KIM-1 presents higher elimination in type $2 \mathrm{DM}$ patients with hyperfiltration than in patients with normal glomerular filtration. NGAL has a similar evolution. These biomarkers-KIM-1 and NGAL-could plead for a deleterious lesional effect of hyperfiltration on the proximal tubule [53].

Nielsen et al. however could not demonstrate a value of urinary KIM-1 that could be predictive of the evolution of glomerular function (GFR) in patients with type $1 \mathrm{DM}$ [63].

According to Nielsen et al. it has no prognostic utility in type $2 \mathrm{DM}$ patients either [64].

3.2.4. Urinary $N$-Acetyl- $\beta$ - $D$ glucosaminidase (NAG). NAG is an enzyme located in the lysosomes of proximal tubular cells [65].

In case of dysfunction, namely, of injury of proximal tubular cells, NAG is eliminated into the urine in higher quantities, being a sensitive tubular biomarker. This can precede the appearance of microalbuminuria in type $1 \mathrm{DM}$ [66].

Elevated serum Cys C levels and urinary NAG activities were found only in normoalbuminurics, not in controls. In addition, elevated urinary ALP and LDH activities were also found in microalbuminurics [67].
Other authors, like Ambade et al., did not find that urinary NAG has clinical significance as an early biomarker of DN [68].

In type $2 \mathrm{DM}$ urinary NAG excretion increases proportionally to the duration of diabetes. It occurs much earlier than albuminuria. NAG can be considered an early tubular biomarker [69].

Assal et al. consider that urinary NAG is the most sensitive biomarker for detecting early damage in diabetic patients [70].

3.2.5. Urinary Angiotensinogen. The renin angiotensin aldosterone system (RAAS) is involved in the pathogenesis of DN. The constitutive elements of RAAS are present at kidney level, defining a local RAAS.

Urinary angiotensinogen can represent a biomarker for the activation of RAAS in DM [71].

High urinary angiotensinogen precedes in type $1 \mathrm{DM}$ patients the occurrence of microalbuminuria [72]. This could have a predictive role in normotensive type $1 \mathrm{DM}$ patients [73].

Urinary angiotensinogen in normoalbuminuric type 2 DM patients is higher than in controls and it increases progressively in microalbuminuric and especially in macroalbuminuric patients [73].

Urinary angiotensinogen can be considered an early biomarker of DN [72].

In type $2 \mathrm{DM}$ patients, urinary angiotensinogen is correlated with alpha-1-microglobulin [8].

Kim et al. did not confirm these observations in a study on type $2 \mathrm{DM}$ patients. They found that the values of urinary angiotensinogen are not different from those of the controls, in normoalbuminuric and microalbuminuric type 2 DM patients, but higher values were described in macroalbuminuric patients [74].

These observations point to the need of further studies necessary for the validation of this biomarker.

Increased urinary angiotensinogen could represent a risk factor in renal and cardiovascular complications [75].

Since activation of RAAS could intervene in the evolution of DN, administration of ACE-I is recommended.

At the same time, urinary angiotensinogen could be a marker for assessing the renoprotective effects of alogliptin to type $2 \mathrm{DM}$ patients [76].

3.2.6. Cystatin C. It is a low molecular weight protein having the role of cysteine protease. Cystatin is produced by the nucleated cells in the body [77].

It is filtered at glomerular level and is reabsorbed in the tubules. Cystatin is used for evaluating renal function. Assessment of GFR by means of cystatin C is considered to be a method that is not influenced by body mass, being comparable and even better than methods using serum creatinine [78].

Serum cystatin is also considered a sensitive biomarker as it detects minor glomerular injury [79].

Urinary cystatin $C$ indicates tubular injury. It increases early in diabetes and prediabetic nephropathy [80]. 
Patients with microalbuminuria present higher values of urinary cystatin $\mathrm{C}$ than those without microalbuminuria, urinary cystatin $\mathrm{C}$ having a predictive role for the progression of diabetic nephropathy (DN) [81].

Urinary cystatin C level could be an independent factor for identifying renal dysfunction in type $2 \mathrm{DM}$ patients with normoalbuminuria, including patients with GFR $<60 / \mathrm{mL} / \mathrm{min} / 1.73 \mathrm{~m}^{2}$ [77]. Uslu et al. find a significant positive correlation between serum cystatin C, urinary NAG, lacticodehydrogenase, alkaline phosphatase activities, and serum creatinine levels [67].

Serum and urinary cystatin $\mathrm{C}$ are useful biomarkers for assessing early nephropathy in type 2 DM [77].

3.2.7. L-FABP (Liver-Type Fatty Acid Binding Protein). Urinary L-FABP is a protein with low molecular weight expressed in the cytoplasm of human proximal tubular cells [82]. It is also expressed at liver level.

Increased urinary L-FABP was found in type $1 \mathrm{DM}$ patients who presented normoalbuminuria, having a predictive role regarding the progression towards microalbuminuria and of microalbuminuria towards macroalbuminuria [83].

Patients with type $2 \mathrm{DM}$ with normoalbuminuria also presented high levels of urinary L-FABP, this protein being considered as a useful biomarker for diagnosing early diabetic nephropathy. In fact, urinary L-FABP has been confirmed as a tubular biomarker by the Ministry of Health and Welfare in Japan [82].

The L-FABP factor is also related to the severity of DN. The values of urinary L-FABP increase with the decline of renal function [84].

Although some authors, like Chou et al., do not ascribe a predictive role to urinary L-FABP in type $2 \mathrm{DM}$ patients [85], others, like Panduru et al., consider that urinary L-FABP is an independent predictor of the progression of DN [86].

3.2.8. Nephrinuria. Nephrine is a transmembrane protein in the structure of the slit diaphragm [87].

In DM podocyte dysfunction is present. $\mathrm{DN}$ is considered a podocytopathy [88]. Injury of the slit diaphragm leads to nephrinuria.

Nephrinuria can occur in some type $1 \mathrm{DM}$ patients prior to microalbuminuria [89]. Nephrinuria was also reported in some normoalbuminuric type $2 \mathrm{DM}$ patients $[62,90]$.

Nephrinuria is related to podocyte injury representing a biomarker of early glomerular injury [91].

Dysregulation of nephrine in podocytes in DN could lead to nephrinuria in normoalbuminuric patients, preceding microalbuminuria [92].

In albuminuric patients, nephrinuria is positively correlated with albuminuria and negatively correlated with GFR, being a biomarker of DN in other phases of DM as well.

Podocyte impairment in DM involves not only nephrine but also other podocyte elements, for example, VEGF. Thus, in normoalbuminuric DM patients nephrinuria is correlated with urinary elimination of VEGF [62].

Tubular biomarkers seem to play an important role in the early diagnosis of DN. They manage to show, in most cases, that microalbuminuria does not represent a reliable biomarker for diagnosing incipient lesions of DN. However, up to now, none of these biomarkers has been established as gold standard for the identification of early DN.

3.3. Markers of Inflammation. DM is accompanied by chronic inflammatory processes affecting the whole body, the kidneys included. Mediators of inflammation, like cytokines and chemokines, are present in these processes. Some of them are useful as markers of inflammation.

3.3.1. Tumour Necrosis Factor Alpha (TNF Alpha). Urinary TNF alpha presents in type 2 DM patients with microalbuminuria and macroalbuminuria higher values than in patients with normoalbuminuria. Urinary TNF alpha is correlated with urinary NAG, a marker of tubular lesions [93].

Cherney et al. analyzed in a complex study on normoalbuminuric type $1 \mathrm{DM}$ patients forty-two urinary cytokines/chemokines. They found that the urinary level of IL6 and IL8, the platelet-derived growth factor, and RANTES are not altered in patients with normal albumin-creatinine ratio.

Higher urinary excretion of these markers is associated with microalbuminuria. Cherney et al. consider that these markers could have a role in assessing the risk of $\mathrm{DN}$ in patients with type 1 DM [94].

In type $1 \mathrm{DM}$ patients, renal hyperfiltration is related to increased excretion of inflammatory cytokines/chemokines [95].

Tashiro et al. found in type 2 DM patients that IL8 is high in early stages of DN and MCP-1 increases in advanced stages [96].

A study on type $2 \mathrm{DM}$ patients with normoalbuminuria and microalbuminuria found higher values of IL8, IP10, MCP-1, G-CSF, EOTAXIN, and RANTES in patients with microalbuminuria than in normoalbuminurics or in controls. Their assessment would be useful in the early diagnosis and treatment of DN [97].

Ibrahim and Rached also found that urinary MCP-1 is higher in patients with microalbuminuria than in normoalbuminurics or healthy controls [98].

3.3.2. Urinary Orosomucoid. Orosomucoid represents a glycoprotein involved in inflammatory processes.

Urinary orosomucoid has higher values in type $1 \mathrm{DM}$ patients with normoalbuminuria than in controls. These values increase in patients with microalbuminuria and macroalbuminuria [99]. Type $2 \mathrm{DM}$ patients presented increased excretion of orosomucoid in the urine, in parallel with the excretion of immunoglobulin G, ceruloplasmin, and transferrin [16]. El-Beblawy et al. appreciate that orosomucoid is a significant independent factor for diabetic microvascular complications and can be considered as an early marker of renal injury [100].

Urinary orosomucoid excretion rate in type $2 \mathrm{DM}$ patients predicts cardiovascular mortality [101].

Urinary markers of inflammation are useful for assessing inflammatory processes in $\mathrm{DN}$, even in early stages. 
3.4. Oxidative Stress Biomarkers. Oxidative stress plays an important part in the development and progression of $\mathrm{DN}$ [102].

3.4.1. Urinary 8-Oxo-7,8-dihydro-2-deoxyguanosine (8oHdG). 8-oHdG is produced secondary to oxidative DNA damage. It is eliminated into the urine without being metabolized [103]. At present, it is considered a marker for oxidative stress.

After a 5-year follow-up, Hinokio et al. find that 8-oxodG in urine is a useful clinical marker to predict the development of diabetic nephropathy in diabetic patients. There was a significant progression of diabetic nephropathy in the patients with higher excretion of 8-oxodG in urine compared with the patients with moderate or lower excretion of 8oxodG [104].

Leinonen et al. reported increased excretion of 8-oHdG in type $1 \mathrm{DM}$ patients 9 years after the onset of disease, mainly related to poor glycemic control [105].

The urinary 8 -oHdG marker of oxidation would be, according to Broedbaek et al., a predictor of long-term mortality in DM [106].

3.4.2. Heart Fatty Acid Binding Protein (H-FABP). Heart fatty acid binding protein (H-FABP) is a marker of distal tubular damage.

In a study on a cohort of type 1 and type $2 \mathrm{DM}$ patients and an assessment of their markers of glomerular lesions (IgG), markers of proximal tubular lesions (urinary KIM-1, NAG, NGAL, and cystatin), and a marker of distal tubular lesions (urinary H-FABP) in relationship with albuminuria and GFR, Nauta et al. reported higher values of urinary NAG, NGAL, and $\mathrm{H}-\mathrm{FABP}$ in normoalbuminurics than in controls. On the other hand, the values of urinary cystatin C were low [107].

This shows that normoalbuminuric DM patients present both proximal and distal tubular lesions.

3.4.3. Urinary Advanced Glycation End Products (AGE). AGE eliminated in the urine induce a toxic tubular effect producing tubular dysfunction.

In type $2 \mathrm{DM}$ patients with normoalbuminuria high values of urinary alpha-1-microglobulin and of urinary KIM1 were found secondary to tubular dysfunction prior to the onset of microalbuminuria. At the same time, urinary AGE were high, being correlated with these markers [108].

Turk et al. found in type $2 \mathrm{DM}$ patients high values of urinary AGE in $50 \%$ of the patients with normoalbuminuria and in $85 \%$ of those with microalbuminuria [109].

Pentosidine, a component of AGE, is a biomarker for their formation and accumulation [110].

Piarulli et al. found in patients with microalbuminuria higher values of pentosidine than in patients with normoalbuminuria [111].

3.4.4. Podocytes. Podocyte lesions appear during DM and $\mathrm{DN}$, respectively, the disease being considered a podocytopathy as mentioned above.

The assessment of podocyte injury can be accomplished by monitoring the number of podocyte cells in the urine or, more precisely, by means of using podocyte urinary biomarkers (podocalyxin and nephrine).

A study on DM patients found that the values of the number of urinary podocytes in normoalbuminuric patients are not significantly different from those of controls. In patients with microalbuminuria and nephrotic syndrome, the number of urinary podocytes is higher. It is correlated with urinary osteopontin and urinary IgM [33].

Urinary podocalyxin originates in the podocyte apical surface, occurring in vesicle form. In DM patients, the podocalyxin level presented higher levels in patients with microalbuminuria than in patients with normoalbuminuria [112].

Another study on DM patients found high values of urinary podocalyxin in more than half of the patients with normoalbuminuria, these values being higher in patients with microalbuminuria and macroalbuminuria.

Urinary podocalyxin is correlated with the values of urinary NAG and of urinary beta 2 microglobulin [113].

Hara et al. consider that urinary podocalyxin can be an early biomarker for detecting early podocyte injury in patients with DM.

Zheng assessed the urinary microRNA profile of podocyte-associated molecules (synaptopodin, podocalyxin, CD2-AP, $\alpha$-actin4, and podocin) as biomarkers in patients with normoalbuminuria, microalbuminuria, and macroalbuminuria and they reported its increase during the progression of DN [114].

\subsubsection{Vascular Endothelial Growth Factor (VEGF). VEGF is} a proangiogenic factor produced mainly by the podocytes at nephron level. Urinary VEGF can be considered a podocyte biomarker.

Urinary VEGF was detected in type 2 DM patients, being correlated in these patients with urinary alpha-1microglobulin, a biomarker for proximal tubular lesions [62].

Kim et al. found that VEGF is excreted at higher values than controls in normoalbuminuric type $2 \mathrm{DM}$ patients. The values increase in patients with microalbuminuria and macroalbuminuria [115].

Fetuin A is glycosylated glycoprotein was considered an inhibitor for ectopic calcium deposition and promoter of insulin resistance. Fetuin A inhibits the calcification of atherosclerotic plaques in diabetes mellitus [116]. It was found that elevated urinary Fetuin A excretion is a risk for development of diabetic nephropathy [117].

3.5. Other Urinary Biomarkers Used in Evaluating Early DN. Numerous urinary markers have been suggested for assessing early DN. Some of them have been introduced in use only recently.

Urinary retinol-binding protein is a low molecular weight protein that was found to have high urinary values (together with NAG) in normoalbuminuric patients, reflecting tubular dysfunction in early DN [118].

The value of serum retinol-binding protein 4 as a biomarker in assessing the severity of coronary artery disease is to be mentioned [119]. 
Urinary retinol-binding protein 4 as a biomarker in assessing DN needs further studies.

Urinary vitamin $\mathrm{D}$ binding protein can plays the role as biomarker. In type $2 \mathrm{DM}$ it is attributed a potential role in early diagnosis of DN [120].

Urinary heme oxygenase-1 was found in type 2 DM patients before the onset of significant albuminuria, thus being a possible biomarker of early DN [121]. In fact oxidative stress activation is expected in DN.

Periostin is a cell adhesion molecule which is not normally present in kidneys. In tubulointerstitial lesions it is however expressed in the kidneys, being eliminated in the urine. This is why urinary periostin could be used as a marker of injury at this level.

Since high levels of periostin can be identified in DM patients before significant albuminuria, periostin could represent a marker of diabetic renal injury [122].

Urinary alpha klotho presents higher values in normoalbuminuric type $2 \mathrm{DM}$ patients than in controls. It can also be a marker of diabetic injury [123].

Analyzing a group of normoalbuminuric, microalbuminuric, and macroalbuminuric type 2 DM patients, Sun et al. noted that the urinary level of microvesicle-bound dipeptidyl peptidase-IV is related to the severity of DN [124].

Recent studies point to the usage of urine-specific microRNA as a biomarker for early stages of DN. Analyzing the studies in the literature, Yang et al. issued the hypothesis that urine-specific microRNA would be a marker that can be used in the early stages of DN [125].

Recently, Argyropoulos highlighted the predictive role of urinary microRNA regarding microalbuminuria in type 1 DM [126].

Adipokine zinc-alpha-2 glycoprotein is assigned to the major histocompatibility complex class I of proteins [127].

Urinary adipokine zinc-alpha-2 glycoprotein is present earlier than microalbuminuria in diabetic nephropathy. It could be a useful biomarker for diagnosing early DN [128]. Lim et al. also appreciate adipokine zinc-alpha-2 glycoprotein as a novel urinary biomarker for normoalbuminuric diabetic nephropathy [129].

3.5.1. Proteomics. At present proteomic investigations are engaged in identification of new urinary biomarkers to be used in the early diagnosis of DN.

In fact, proteomics studies noted the fact that microalbuminuria is not a perfect biomarker for early detection of DN $[130,131]$.

Urinary proteomics begins to stand out as a noninvasive method of detecting early DN.

Among proteomics studies on diagnosing DN we can mention those of Zürbig et al., who reported that collagen fragments were a prominent biomarker 3-5 years before the onset of microalbuminuria [132].

A potential role is also attributed to exosome proteomics for identifying new biomarkers for DN [133]. Zubiri et al. showed a panel of 3 proteins which is differentially present in urinary exosomes from DN patients [134]. Urinary proteomic analysis can have an important role in the implementation of new biomarkers in DN [135].
At present, the prospect of discovering new biomarkers in DM and DN respectively is incumbent both on proteomics and on genomics, transcriptomics, and metabolomics [136].

\section{Conclusions}

Urinary biomarkers allow an assessment of early DN.

Microalbuminuria, although frequently contested as a biomarker of early DN, is used so far as reference biomarker in assessing other urinary biomarkers in early DN. Until present there is no other biomarker that can substitute in practice microalbuminuria, the new biomarkers being sustained by limited studies and requiring validation.

The concomitant assessment of several urinary biomarkers in relationship with microalbuminuria could represent at present a method of diagnosing early DN. The great progress in discovering new biomarkers could lead to the development of an "ideal" urinary biomarker to detect early diabetic DN in the future.

Progresses in the field of urinary biomarkers in $\mathrm{DN}$, promising both in proteomics and in other modern techniques, develop remarkably at present.

\section{Disclosure}

The supporting source had no involvement in study design, in collection, analysis, and interpretation of data, in the writing of the report, and in the decision to submit the paper for publication.

\section{Competing Interests}

The authors declare that they have no competing interests.

\section{Authors' Contributions}

Cristina Gluhovschi and Gheorghe Gluhovschi contributed equally to this paper.

\section{Acknowledgments}

This research received funding from an Internal Grant of "Victor Babes" University of Medicine and Pharmacy Timisoara, PIII-C1-PCFI-2014/2015.

\section{References}

[1] R. J. Macisaac, E. I. Ekinci, and G. Jerums, "Markers of and risk factors for the development and progression of diabetic kidney disease," American Journal of Kidney Diseases, vol. 63, no. 2, pp. S39-S62, 2014.

[2] M. Narres, H. Claessen, S. Droste et al., "The incidence of end-stage renal disease in the diabetic (compared to the nondiabetic) population: a systematic review," PLoS ONE, vol. 11, no. 1, Article ID e0147329, 2016.

[3] E. Lioudaki, K. G. Stylianou, I. Petrakis et al., "Increased urinary excretion of podocyte markers in normoalbuminuric patients with diabetes," Nephron, vol. 131, no. 1, pp. 34-42, 2015. 
[4] N. Banu, H. Hara, M. Okamura, G. Egusa, and M. Yamakido, "Urinary excretion of type IV collagen and laminin in the evaluation of nephropathy in NIDDM: comparison with urinary albumin and markers of tubular dysfunction and/or damage," Diabetes Research and Clinical Practice, vol. 29, no. 1, pp. 57-67, 1995.

[5] P. Kubisz, L. Stanciaková, J. Staško, P. Galajda, and M. Mokáň, "Endothelial and platelet markers in diabetes mellitus type 2," World Journal of Diabetes, vol. 6, no. 3, pp. 423-431, 2015.

[6] G. Tramonti and Y. S. Kanwar, "Tubular biomarkers to assess progression of diabetic nephropathy," Kidney International, vol. 79, no. 10, pp. 1042-1044, 2011.

[7] T. Terami, J. Wada, K. Inoue et al., "Urinary angiotensinogen is a marker for tubular injuries in patients with type 2 diabetes," International Journal of Nephrology and Renovascular Disease, vol. 6, pp. 233-240, 2013.

[8] M. Eriguchi, R. Yotsueda, K. Torisu et al., "Assessment of urinary angiotensinogen as a marker of podocyte injury in proteinuric nephropathies," American Journal of PhysiologyRenal Physiology, vol. 310, no. 4, pp. F322-F333, 2016.

[9] A. Matheson, M. D. P. Willcox, J. Flanagan, and B. J. Walsh, "Urinary biomarkers involved in type 2 diabetes: a review," Diabetes/Metabolism Research and Reviews, vol. 26, no. 3, pp. 150-171, 2010.

[10] C. Y. Hong and K. S. Chia, "Markers of diabetic nephropathy," Journal of Diabetes and Its Complications, vol. 12, no. 1, pp. 4360, 1998.

[11] J. H. Warram, L. J. Scott, L. S. Hanna et al., "Progression of microalbuminuria to proteinuria in type 1 diabetes: nonlinear relationship with hyperglycemia," Diabetes, vol. 49, no. 1, pp. 94$100,2000$.

[12] P. Fioretto, M. W. Steffes, and M. Mauer, "Glomerular structure in nonproteinuric IDDM patients with various levels of albuminuria," Diabetes, vol. 43, no. 11, pp. 1358-1364, 1994.

[13] K. McKenna and C. Thompson, "Microalbuminuria: a marker to increased renal and cardiovascular risk in diabetes mellitus," Scottish Medical Journal, vol. 42, no. 4, pp. 99-104, 1997.

[14] P. Hovind, L. Tarnow, P. Rossing et al., "Predictors for the development of microalbuminuria and macroalbuminuria in patients with type 1 diabetes: inception cohort study," British Medical Journal, vol. 328, no. 7448, pp. 1105-1108, 2004.

[15] I. H. de Boer, T. C. Rue, P. A. Cleary et al., "Long-term renal outcomes of patients with type 1 diabetes mellitus and microalbuminuria: an analysis of the Diabetes Control and Complications Trial/Epidemiology of Diabetes Interventions and Complications cohort," Archives of Internal Medicine, vol. 171, no. 5, pp. 412-420, 2011.

[16] G. Zoppini, G. Targher, M. Chonchol et al., "Predictors of estimated GFR decline in patients with type 2 diabetes and preserved kidney function," Clinical Journal of the American Society of Nephrology, vol. 7, no. 3, pp. 401-408, 2012.

[17] B. A. Perkins, L. H. Ficociello, B. E. Ostrander et al., "Microalbuminuria and the risk for early progressive renal function decline in type 1 diabetes," Journal of the American Society of Nephrology, vol. 18, no. 4, pp. 1353-1361, 2007.

[18] D. J. Newman, M. B. Mattock, A. B. Dawnay et al., "Systematic review on urine albumin testing for early detection of diabetic complications," Health Technology Assessment, vol. 9, no. 30, 2005.

[19] H.-H. Parving, J. B. Lewis, M. Ravid, G. Remuzzi, and L. G. Hunsicker, "Prevalence and risk factors for microalbuminuria in a referred cohort of type II diabetic patients: a global perspective," Kidney International, vol. 69, no. 11, pp. 2057-2063, 2006.

[20] B. Lu, J. Wen, X. Y. Song et al., "High prevalence of albuminuria in population-based patients diagnosed with type 2 diabetes in the Shanghai downtown," Diabetes Research and Clinical Practice, vol. 75, no. 2, pp. 184-192, 2007.

[21] N. Ismail, B. Becker, P. Strzelczyk, and E. Ritz, "Renal disease and hypertension in non-insulin-dependent diabetes mellitus," Kidney International, vol. 55, no. 1, pp. 1-28, 1999.

[22] S.-I. Araki, M. Haneda, D. Koya et al., "Reduction in microalbuminuria as an integrated indicator for renal and cardiovascular risk reduction in patients with type 2 diabetes," Diabetes, vol. 56, no. 6, pp. 1727-1730, 2007.

[23] R. G. Nelson, P. H. Bennett, G. J. Beck et al., "Development and progression of renal disease in Pima Indians with non- insulindependent diabetes mellitus," The New England Journal of Medicine, vol. 335, no. 22, pp. 1636-1642, 1996.

[24] S. C. W. Tang, J. C. K. Leung, and K. N. Lai, "Diabetic tubulopathy: an emerging entity," in Diabetes and the Kidney, K. N. Lai and S. C. W. Tang, Eds., Karger, 2011.

[25] K. Kunika, T. Yamaoka, and M. Itakura, "Damage of chargedependent renal tubular reabsorption causes diabetic microproteinuria," Diabetes Research and Clinical Practice, vol. 36, no. 1, pp. 1-9, 1997.

[26] G. Currie, G. Mc Kay, and C. Delles, "Biomarkers in diabetic nephropathy: present and future," World Journal of Diabetes, vol. 5, no. 6, pp. 763-776, 2014.

[27] T. Narita, H. Sasaki, M. Hosoba et al., "Parallel increase in urinary excretion rates of immunoglobulin $\mathrm{G}$, ceruloplasmin, transferrin, and orosomucoid in normoalbuminuric type 2 diabetic patients," Diabetes Care, vol. 27, no. 5, pp. 1176-1181, 2004.

[28] M. Kanauchi, Y. Akai, and T. Hashimoto, “Transferrinuria in type 2 diabetic patients with early nephropathy and tubulointerstitial injury," European Journal of Internal Medicine, vol. 13, no. 3, pp. 190-193, 2002.

[29] B. Quiroga, D. Arroyo, and G. de Arriba, "Present and future in the treatment of diabetic kidney disease," Journal of Diabetes Research, vol. 2015, Article ID 801348, 13 pages, 2015.

[30] T. Kazumi, T. Hozumi, Y. Ishida et al., "Increased urinary transferrin excretion predicts microalbuminuria in patients with type 2 diabetes," Diabetes Care, vol. 22, no. 7, pp. 1176-1180, 1999.

[31] A. Cohen-Bucay and G. Viswanathan, "Urinary markers of glomerular injury in diabetic nephropathy," International Journal of Nephrology, vol. 2012, Article ID 146987, 11 pages, 2012.

[32] C. Wang, C. Li, W. Gong, and T. Lou, "New urinary biomarkers for diabetic kidney disease," Biomarker Research, vol. 1, article 9, 2013.

[33] M. Yamazaki, S. Ito, A. Usami et al., "Urinary excretion rate of ceruloplasmin in non-insulin-dependent diabetic patients with different stages of nephropathy," European Journal of Endocrinology, vol. 132, no. 6, pp. 681-687, 1995.

[34] L. X. Qin, X. Zeng, and G. Huang, "Changes in serum and urine ceruloplasmin concentrations in type 2 diabetes," Zhong Nan Da Xue Xue Bao Yi Xue Ban, vol. 29, no. 2, pp. 208-211, 2004.

[35] J. T. Tamsma, J. van den Born, J. A. Bruijn et al., "Expression of glomerular extracellular matrix components in human diabetic nephropathy: decrease of heparan sulphate in the glomerular basement membrane," Diabetologia, vol. 37, no. 3, pp. 313-320, 1994. 
[36] T. Fiseha, "Urinary biomarkers for early diabetic nephropathy in type 2 diabetic patients," Biomarker Research, vol. 3, article 16, 2015.

[37] N. Kotajima, T. Kimura, T. Kanda et al., “Type IV collagen as an early marker for diabetic nephropathy in non-insulindependent diabetes mellitus," Journal of Diabetes and its Complications, vol. 14, no. 1, pp. 13-17, 2000.

[38] H. Takizawa, T. Satoh, A. Kurusu et al., "Increase of urinary type IV collagen in normoalbuminuric patients with impaired glucose tolerance," Nephron, vol. 79, no. 4, pp. 474-475, 1998.

[39] H. Okonogi, M. Nishimura, Y. Utsunomiya et al., "Urinary type IV collagen excretion reflects renal morphological alterations and type IV collagen expression in patients with type 2 diabetes mellitus," Clinical Nephrology, vol. 55, no. 5, pp. 357-364, 2001.

[40] S. Ming, Z. Qi, L. Wang, and K. Zhu, "Urinary type IV collagen: a specific indicator of incipient diabetic nephropathy," Chinese Medical Journal, vol. 115, no. 3, pp. 389-394, 2002.

[41] S. Kado, A. Aoki, S. Wada et al., "Urinary type IV collagen as a marker for early diabetic nephropathy," Diabetes Research and Clinical Practice, vol. 31, no. 1-3, pp. 103-108, 1996.

[42] I. Ueta, K. Takamatsu, and K. Hashimoto, "Urinary glycosaminoglycans in patients with incipient diabetic nephropathy," Nihon Jinzo Gakkai Shi, vol. 37, no. 1, pp. 17-23, 1995.

[43] O. Torffvit, "Urinary sulphated glycosaminoglycans and TammHorsfall protein in type 1 diabetic patients," Scandinavian Journal of Urology and Nephrology, vol. 33, no. 5, pp. 328-332, 1999.

[44] Y. Uehara, H. Makino, K. Seiki, and Y. Urade, "Urinary excretions of lipocalin-type prostaglandin D synthase predict renal injury in type-2 diabetes: a cross-sectional and prospective multicentre study," Nephrology Dialysis Transplantation, vol. 24, no. 2, pp. 475-482, 2009.

[45] K. Kuboki, H. Tada, K. Shin, Y. Oshima, and S. Isogai, "Relationship between urinary excretion of fibronectin degradation products and proteinuria in diabetic patients, and their suppression after continuous subcutaneous heparin infusion," Diabetes Research and Clinical Practice, vol. 21, no. 1, pp. 61-66, 1993.

[46] A. L. Al-Malki, "Assessment of urinary osteopontin in association with podocyte for early predication of nephropathy in diabetic patients," Disease Markers, vol. 2014, Article ID 493736, 5 pages, 2014.

[47] K. Mise, J. Hoshino, T. Ueno et al., "Prognostic value of tubulointerstitial lesions, urinary $\mathrm{N}$-acetyl- $\beta$-d-glucosaminidase, and urinary $\beta 2$-microglobulin in patients with type 2 diabetes and biopsy-proven diabetic nephropathy," Clinical Journal of the American Society of Nephrology, vol. 11, no. 4, pp. 593-601, 2016.

[48] K. M. Schmidt-Ott, K. Mori, Y. L. Jau et al., "Dual action of neutrophil gelatinase-associated lipocalin," Journal of the American Society of Nephrology, vol. 18, no. 2, pp. 407-413, 2007.

[49] D. Bolignano, A. Lacquaniti, G. Coppolino et al., "Neutrophil gelatinase-associated lipocalin as an early biomarker of nephropathy in diabetic patients," Kidney \& Blood Pressure Research, vol. 32, no. 2, pp. 91-98, 2009.

[50] Z. Yürük Yıldırım, A. Nayır, A. Yılmaz, A. Gedikbaşı, and R. Bundak, "Neutrophil gelatinase-associated lipocalin as an early sign of diabetic kidney injury in children," Journal of Clinical Research in Pediatric Endocrinology, vol. 7, no. 4, pp. 274-279, 2015.

[51] A. Lacquaniti, V. Donato, B. Pintaudi et al., "Normoalbuminuric' diabetic nephropathy: tubular damage and NGAL," Acta Diabetologica, vol. 50, no. 6, pp. 935-942, 2013.
[52] J. A. de Carvalho, E. Tatsch, B. S. Hausen et al., "Urinary kidney injury molecule-1 and neutrophil gelatinase-associated lipocalin as indicators of tubular damage in normoalbuminuric patients with type 2 diabetes," Clinical Biochemistry, vol. 49, no. 3, pp. 232-236, 2016.

[53] W.-J. Fu, S.-L. Xiong, Y.-G. Fang et al., "Urinary tubular biomarkers in short-term type 2 diabetes mellitus patients: a cross-sectional study," Endocrine, vol. 41, no. 1, pp. 82-88, 2012.

[54] V. Garg, M. Kumar, H. S. Mahapatra, A. Chitkara, A. K. Gadpayle, and V. Sekhar, "Novel urinary biomarkers in prediabetic nephropathy," Clinical and Experimental Nephrology, vol. 19, no. 5, pp. 895-900, 2015.

[55] Y.-H. Yang, X.-J. He, S.-R. Chen, L. Wang, E.-M. Li, and L.-Y. Xu, "Changes of serum and urine neutrophil gelatinase-associated lipocalin in type-2 diabetic patients with nephropathy: one year observational follow-up study," Endocrine, vol. 36, no. 1, pp. 4551, 2009.

[56] M. H. Weber and R. Verwiebe, " $\alpha 1-$ microglobulin (protein $\mathrm{HC}$ ): features of a promising indicator of proximal tubular dysfunction," European Journal of Clinical Chemistry and Clinical Biochemistry, vol. 30, no. 10, pp. 683-691, 1992.

[57] C.-Y. Hong, K. Hughes, K.-S. Chia, V. Ng, and S.-L. Ling, "Urinary $\alpha 1$-microglobulin as a marker of nephropathy in type 2 diabetic Asian subjects in Singapore," Diabetes Care, vol. 26, no. 2, pp. 338-342, 2003.

[58] L. Petrica, M. Petrica, A. Vlad et al., "Proximal tubule dysfunction is dissociated from endothelial dysfunction in normoalbuminuric patients with type 2 diabetes mellitus: a cross-sectional study," Nephron Clinical Practice, vol. 118, no. 2, pp. c155-c164, 2011.

[59] H. Wainai, F. Katsukawa, I. Takei, H. Maruyama, K. Kataoka, and T. Saruta, "Influence of glycemic control and hypertension on urinary microprotein excretion in non-insulin-dependent diabetes mellitus," Journal of Diabetic Complications, vol. 5, no. 2-3, pp. 160-161, 1991.

[60] N. Shore, R. Khurshid, and M. Saleem, "Alpha-1 microglobulin: a marker for early detection of tubular disorders in diabetic nephropathy," Journal of Ayub Medical College, Abbottabad, vol. 22, no. 4, pp. 53-55, 2010.

[61] J. V. Bonventre, "Kidney injury molecule-1: a translational journey," Transactions of the American Clinical and Climatological Association, vol. 125, pp. 293-299, 2014.

[62] L. Petrica, A. Vlad, G. Gluhovschi et al., "Proximal tubule dysfunction is associated with podocyte damage biomarkers nephrin and vascular endothelial growth factor in type 2 diabetes mellitus patients: a cross-sectional study," PLOS ONE, vol. 9, no. 11, Article ID e112538, 2014.

[63] S. E. Nielsen, K. J. Schjoedt, A. S. Astrup et al., "Neutrophil Gelatinase-Associated Lipocalin (NGAL) and Kidney Injury Molecule 1 (KIM1) in patients with diabetic nephropathy: a cross-sectional study and the effects of lisinopril," Diabetic Medicine, vol. 27, no. 10, pp. 1144-1150, 2010.

[64] S. E. Nielsen, H. Reinhard, D. Zdunek et al., "Tubular markers are associated with decline in kidney function in proteinuric type 2 diabetic patients," Diabetes Research and Clinical Practice, vol. 97, no. 1, pp. 71-76, 2012.

[65] C. Bazzi, C. Petrini, V. Rizza et al., "Urinary N-acetyl- $\beta$ glucosaminidase excretion is a marker of tubular cell dysfunction and a predictor of outcome in primary glomerulonephritis," Nephrology Dialysis Transplantation, vol. 17, no. 11, pp. 18901896, 2002. 
[66] A. P. Jones, S. Lock, and K. D. Griffiths, "Urinary N-acetyl- $\beta$ glucosaminidase activity in type I diabetes mellitus," Annals of Clinical Biochemistry, vol. 32, no. 1, pp. 58-62, 1995.

[67] S. Uslu, B. Efe, Ö. Alataş et al., "Serum cystatin C and urinary enzymes as screening markers of renal dysfunction in diabetic patients," Journal of Nephrology, vol. 18, no. 5, pp. 559-567, 2005.

[68] V. Ambade, P. Singh, B. L. Somani, and D. Basannar, "Urinary $\mathrm{N}$-acetyl beta glucosaminidase and gamma glutamyl transferase as early markers of diabetic nephropathy," Indian Journal of Clinical Biochemistry, vol. 21, no. 2, pp. 142-148, 2006.

[69] D. N. Patel and K. Kalia, "Efficacy of urinary N-acetyl- $\beta$-Dglucosaminidase to evaluate early renal tubular damage as a consequence of type 2 diabetes mellitus: a cross-sectional study," International Journal of Diabetes in Developing Countries, vol. 35, supplement 3, pp. 449-457, 2015.

[70] H. S. Assal, S. Tawfeek, E. A. Rasheld, D. El-Lebedy, and E. H. Thabet, "Serum cystatin $\mathrm{C}$ and tubular urinary enzymes as biomarkers: a renal dysfunction in type 2 diabetes mellitus," Clinical Medicine Insights: Endocrinology and Diabetes, vol. 6, no. 7, pp. 7-13, 2013.

[71] M. Kamiyama, A. Zsombok, and H. Kobori, "Urinary angiotensinogen as a novel early biomarker of intrarenal reninangiotensin system activation in experimental type 1 diabetes," Journal of Pharmacological Sciences, vol. 119, no. 4, pp. 314-323, 2012.

[72] T. Saito, M. Urushihara, Y. Kotani, S. Kagami, and H. Kobori, "Increased urinary angiotensinogen is precedent to increased urinary albumin in patients with type 1 diabetes," American Journal of the Medical Sciences, vol. 338, no. 6, pp. 478-480, 2009.

[73] Z. Zhuang, Q. Bai, L. A, T. Liang, D. Zheng, and Y. Wang, "Increased urinary angiotensinogen precedes the onset of albuminuria in normotensive type 2 diabetic patients," International Journal of Clinical and Experimental Pathology, vol. 8, no. 9, pp. 11464-11469, 2015.

[74] S. S. Kim, S. H. Song, I. J. Kim et al., "Clinical implication of urinary tubular markers in the early stage of nephropathy with type 2 diabetic patients," Diabetes Research and Clinical Practice, vol. 97, no. 2, pp. 251-257, 2012.

[75] M. Sawaguchi, S.-I. Araki, H. Kobori et al., "Association between urinary angiotensinogen levels and renal and cardiovascular prognoses in patients with type 2 diabetes mellitus," Journal of Diabetes Investigation, vol. 3, no. 3, pp. 318-324, 2012.

[76] T. Mizushige, H. Kobori, Y. Nishijima et al., "Urinary angiotensinogen could be a prognostic marker of renoprotective effects of alogliptin in patients with type 2 diabetes," Journal of Diabetes Research, vol. 2015, Article ID 517472, 7 pages, 2015.

[77] Y. K. Jeon, M. R. Kim, J. E. Huh et al., "Cystatin C as an early biomarker of nephropathy in patients with type 2 diabetes," Journal of Korean Medical Science, vol. 26, no. 2, pp. 258-263, 2011.

[78] W. D. Comper, T. M. Osicka, and G. Jerums, "High prevalence of immuno-unreactive intact albumin in urine of diabetic patients," American Journal of Kidney Diseases, vol. 41, no. 2, pp. 336-342, 2003.

[79] X. Rao, M. Wan, C. Qiu, and C. Jiang, "Role of cystatin C in renal damage and the optimum cut-off point of renal damage among patients with type 2 diabetes mellitus," Experimental and Therapeutic Medicine, vol. 8, no. 3, pp. 887-892, 2014.

[80] V. Garg, M. Kuman, H. S. Mahapatra, A. Chitkora, A. K. Gadpoyle, and V. Sekhan, "Novel urinary biomarkers in prediabetic nephropathy," Clinical and Experimental Nephrology, vol. 19, no. 5, pp. 895-890, 2015.

[81] S. S. Kim, S. H. Song, I. J. Kim et al., "Urinary cystatin C and tubular proteinuria predict progression of diabetic nephropathy," Diabetes Care, vol. 36, no. 3, pp. 656-661, 2013.

[82] A. Kamijo-Ikemori, T. Sugaya, T. Yasuda et al., "Clinical significance of urinary liver-type fatty acid-binding protein in diabetic nephropathy of type 2 diabetic patients," Diabetes Care, vol. 34, no. 3, pp. 691-696, 2011.

[83] S. E. Nielsen, T. Sugaya, P. Hovind, T. Baba, H.-H. Parving, and P. Rossing, "Urinary liver-type fatty acid-binding protein predicts progression to nephropathy in type 1 diabetic patients," Diabetes Care, vol. 33, no. 6, pp. 1320-1324, 2010.

[84] V. Viswanathan, S. Sivakumar, V. Sekar, D. M. Umapathy, and S. Kumpatla, "Clinical significance of urinary liver-type fatty acid binding protein at various stages of nephropathy," Indian Journal of Nephrology, vol. 25, no. 5, pp. 269-273, 2015.

[85] K.-M. Chou, C.-C. Lee, C.-H. Chen, and C.-Y. Sun, "Clinical value of NGAL, L-FABP and albuminuria in predicting GFR decline in type 2 diabetes mellitus patients," PLOS ONE, vol. 8, no. 1, article e54863, 2013.

[86] N. M. Panduru, C. Forsblom, M. Saraheimo et al., "Urinary liver-type fatty acid-binding protein and progression of diabetic nephropathy in type 1 diabetes," Diabetes Care, vol. 36, no. 7, pp. 2077-2083, 2013.

[87] G. I. Welsh and M. A. Saleem, "Nephrin-signature molecule of the glomerular podocyte?" The Journal of Pathology, vol. 220, no. 3, pp. 328-337, 2010.

[88] F. N. Ziyadeh and G. Wolf, "Pathogenesis of the podocytopathy and proteinuria in diabetic glomerulopathy," Current Diabetes Reviews, vol. 4, no. 1, pp. 39-45, 2008.

[89] A. Pätäri, C. Forsblom, M. Havana, H. Taipale, P.-H. Groop, and H. Holthöfer, "Nephrinuria in diabetic nephropathy of type 1 diabetes," Diabetes, vol. 52, no. 12, pp. 2969-2974, 2003.

[90] D. P. K. Ng, B.-C. Tai, E. Tan et al., "Nephrinuria associates with multiple renal traits in type 2 diabetes," Nephrology Dialysis Transplantation, vol. 26, no. 8, pp. 2508-2514, 2011.

[91] Y. Kandasamy, R. Smith, E. R. Lumbers, and D. Rudd, "Nephrin a biomarker of early glomerular injury," Biomarker Research, vol. 2, no. 1, p. 21, 2014.

[92] B. Jim, M. Ghanta, A. Qipo et al., "Dysregulated nephrin in diabetic nephropathy of type 2 diabetes: a cross sectional study," PLoS ONE, vol. 7, no. 5, Article ID e36041, 2012.

[93] J. F. Navarro, C. Mora, M. Gómez, M. Muros, C. LópezAguilar, and J. García, "Influence of renal involvement on peripheral blood mononuclear cell expression behaviour of tumour necrosis factor- $\alpha$ and interleukin- 6 in type 2 diabetic patients," Nephrology Dialysis Transplantation, vol. 23, no. 3, pp. 919-926, 2008.

[94] D. Z. I. Cherney, J. W. Scholey, D. Daneman et al., "Urinary markers of renal inflammation in adolescents with type 1 diabetes mellitus and normoalbuminuria," Diabetic Medicine, vol. 29, no. 10, pp. 1297-1302, 2012.

[95] R. Har, J. W. Scholey, D. Daneman et al., "The effect of renal hyperfiltration on urinary inflammatory cytokines/chemokines in patients with uncomplicated type 1 diabetes mellitus," Diabetologia, vol. 56, no. 5, pp. 1166-1173, 2013.

[96] K. Tashiro, I. Koyanagi, A. Saitoh et al., "Urinary levels of monocyte chemoattractant protein-1 (MCP-1) and interleukin-8 (IL8 ), and renal injuries in patients with type 2 diabetic nephropathy," Journal of Clinical Laboratory Analysis, vol. 16, no. 1, pp. 1-4, 2002. 
[97] J. Liu, Z. Zhao, M. D. P. Willcox, B. Xu, and B. Shi, "Multiplex bead analysis of urinary cytokines of type 2 diabetic patients with normo- and microalbuminuria," Journal of Immunoassay and Immunochemistry, vol. 31, no. 4, pp. 279-289, 2010.

[98] S. Ibrahim and L. Rashed, "Correlation of urinary monocyte chemo-attractant protein-1 with other parameters of renal injury in type-II diabetes mellitus," Saudi Journal of Kidney Diseases and Transplantation, vol. 19, no. 6, pp. 911-917, 2008.

[99] H. Jiang, G. Guan, R. Zhang et al., "Increased urinary excretion of orosomucoid is a risk predictor of diabetic nephropathy," Nephrology, vol. 14, no. 3, pp. 332-337, 2009.

[100] N. M. El-Beblawy, N. G. Andrawes, E. A. Ismail, B. E. Enany, H. S. Abou El-Seoud, and M. A. Erfan, "Serum and Urinary orosomucoid in young patients with type 1 diabetes: a link between inflammation, microvascular complications, and subclinical atherosclerosis," Clinical and Applied Thrombosis/ Hemostasis, 2016.

[101] M. S. Christiansen, E. Hommel, E. Magid, and B. FeldtRasmussen, "Orosomucoid in urine predicts cardiovascular and over-all mortality in patients with type II diabetes," Diabetologia, vol. 45, no. 1, pp. 115-120, 2002.

[102] H. Ha and H. B. Lee, "Oxidative stress in diabetic nephropathy: basic and clinical information," Current Diabetes Reports, vol. 1, no. 3, pp. 282-287, 2001.

[103] L. L. Wu, C. C. Chiou, P. Y. Chang, and J. T. Wu, "Urinary 8OHdG: a marker of oxidative stress to DNA and a risk factor for cancer, atherosclerosis and diabetics," Clinica Chemica Acta, vol. 339, no. 1-2, pp. 1-9, 2004.

[104] Y. Hinokio, S. Suzuki, M. Hirai, C. Suzuki, M. Suzuki, and T. Toyota, "Urinary excretion of 8-oxo-7, 8-dihydro-2' deoxyguanosine as a predictor of the development of diabetic nephropathy," Diabetologia, vol. 45, no. 6, pp. 877-882, 2002.

[105] J. Leinonen, T. Lehtimäki, S. Toyokuni et al., "New biomarker evidence of oxidative DNA damage in patients with noninsulin-dependent diabetes mellitus," FEBS Letters, vol. 417, no. 1, pp. 150-152, 1997.

[106] K. Broedbaek, A. Weimann, E. S. Stovgaard, and H. E. Poulsen, "Urinary 8-oxo-7,8-dihydro-2I-deoxyguanosine as a biomarker in type 2 diabetes," Free Radical Biology and Medicine, vol. 51, no. 8, pp. 1473-1479, 2011.

[107] F. L. Nauta, W. E. Boertien, S. J. L. Bakker et al., "Glomerular and tubular damage markers are elevated in patients with diabetes," Diabetes Care, vol. 34, no. 4, pp. 975-981, 2011.

[108] L. Petrica, A. Vlad, G. Gluhovschi et al., "Glycated peptides are associated with proximal tubule dysfunction in type 2 diabetes mellitus," International Journal of Clinical and Experimental Medicine, vol. 8, no. 2, pp. 2516-2525, 2015.

[109] N. Turk, A. Mornar, V. Mrzljak, and Z. Turk, "Urinary excretion of advanced glycation endproducts in patients with type 2 diabetes and various stages of proteinuria," Diabetes and Metabolism, vol. 30, no. 2, pp. 187-192, 2004.

[110] A. A. Ghanem, A. Elewa, and L. F. Arafa, "Pentosidine and Ncarboxymethyl-lysine: biomarkers for type 2 diabetic retinopathy," European Journal of Ophthalmology, vol. 21, no. 1, pp. 4854, 2011.

[111] F. Piarulli, G. Sartore, A. Ceriello et al., "Relationship between glyco-oxidation, antioxidant status and microalbuminuria in type 2 diabetic patients," Diabetologia, vol. 52, no. 7, pp. 14191425, 2009.
[112] M. Shoji, K. Kobayashi, M. Takemoto, Y. Sato, and K. Yokote, "Urinary podocalyxin levels were associated with urinary albumin levels among patients with diabetes," Biomarkers, vol. 21, no. 2, pp. 164-167, 2015.

[113] M. Hara, K. Yamagata, Y. Tomino et al., "Urinary podocalyxin is an early marker for podocyte injury in patients with diabetes: establishment of a highly sensitive ELISA to detect urinary podocalyxin," Diabetologia, vol. 55, no. 11, pp. 2913-2919, 2012.

[114] M. Zheng, L.-L. Lv, J. Ni et al., "Urinary podocyte-associated mRNA profile in various stages of diabetic nephropathy," PLoS ONE, vol. 6, no. 5, Article ID e20431, 2011.

[115] N. H. Kim, K. B. Kim, D. L. Kim et al., "Plasma and urinary vascular endothelial growth factor and diabetic nephropathy in type 2 diabetes mellitus," Diabetic Medicine, vol. 21, no. 6, pp. 545-551, 2004.

[116] M. Emoto, K. Mori, E. Lee et al., "Fetuin-A and atherosclerotic calcified plaque in patients with type 2 diabetes mellitus," Metabolism: Clinical and Experimental, vol. 59, no. 6, pp. 873878, 2010.

[117] K. Inoue, J. Wada, J. Eguchi et al., "Urinary fetuin-A is a novel marker for diabetic nephropathy in type 2 diabetes identified by lectin microarray," PLoS ONE, vol. 8, no. 10, Article ID e77118, 2013.

[118] M. A. K. Salem, S. A. El-Habashy, O. M. Saeid, M. M. K. El-Tawil, and P. H. Tawfik, "Urinary excretion of N-acetyl- $\beta$ $\mathrm{D}$-glucosaminidase and retinol binding protein as alternative indicators of nephropathy in patients with type 1 diabetes mellitus," Pediatric Diabetes, vol. 3, no. 1, pp. 37-41, 2002.

[119] V. Lambadiari, N. P. E. Kadoglou, V. Stasinos et al., "Serum levels of retinol-binding protein- 4 are associated with the presence and severity of coronary artery disease," Cardiovascular Diabetology, vol. 13, no. 1, article 121, 2014.

[120] A. Shoukry, S. E.-A. Bdeer, and R. H. El-Sokkary, "Urinary monocyte chemoattractant protein-1 and vitamin D-binding protein as biomarkers for early detection of diabetic nephropathy in type 2 diabetes mellitus," Molecular and Cellular Biochemistry, vol. 408, no. 1, pp. 25-35, 2015.

[121] Z. Li, Y. Xu, Y. Nie, and Z. Zhao, "Urinary heme oxygenase-1 as a potential biomarker for early diabetic nephropathy," Nephrology (Carlton, Vic.), 2016.

[122] B. Satirapoj, S. Tassanasorn, M. Charoenpitakchai, and O. Supasyndh, "Periostin as a tissue and urinary biomarker of renal injury in type 2 diabetes mellitus," PLoS ONE, vol. 10, no. 4, Article ID e0124055, 2015.

[123] E. Y. Lee, S. S. Kim, J.-S. Lee et al., "Soluble $\alpha$-klotho as a novel biomarker in the early stage of nephropathy in patients with type 2 diabetes," PLoS ONE, vol. 9, no. 8, article e102984, 2014.

[124] A.-L. Sun, J.-T. Deng, G.-J. Guan et al., "Dipeptidyl peptidase-IV is a potential molecular biomarker in diabetic kidney disease," Diabetes and Vascular Disease Research, vol. 9, no. 4, pp. 301308, 2012.

[125] Y. Yang, L. Xiao, J. Li, Y. S. Kanwar, F. Liu, and L. Sun, "Urine miRNAs: potential biomarkers for monitoring progression of early stages of diabetic nephropathy," Medical Hypotheses, vol. 81, no. 2, pp. 274-278, 2013.

[126] C. Argyropoulos, K. Wang, J. Bernardo et al., "Urinary MicroRNA profiling predicts the development of microalbuminuria in patients with type 1 Diabetes," Journal of Clinical Medicine, vol. 4, no. 7, pp. 1495-1517, 2015. 
[127] M. W. Kennedy, A. P. Heikema, A. Cooper, P. J. Bjorkman, and L. M. Sanchez, "Hydrophobic ligand binding by Zn- $\alpha 2-$ glycoprotein, a soluble fat-depleting factor related to major histocompatibility complex proteins," Journal of Biological Chemistry, vol. 276, no. 37, pp. 35008-35013, 2001.

[128] Y. Wang, Y. M. Li, S. Zhang, J. Y. Zhao, and C. Y. Liu, "Adipokine zinc- $\alpha$-2- glycoprotein as novel urinary biomarker presents early than microalbuminuria in diabetic nephropathy," Journal of International Medical Research, vol. 44, no. 2, pp. 278-286, 2016.

[129] S. C. Lim, D. Q. Liying, W. C. Toy et al., "Adipocytokine zinc $\alpha 2$ glycoprotein (ZAG) as a novel urinary biomarker for normoalbuminuric diabetic nephropathy," Diabetic Medicine, vol. 29, no. 7, pp. 945-949, 2012.

[130] V. Thongboonkerd, "Study of diabetic nephropathy in the proteomic era," Diabetes and the Kidney, vol. 170, pp. 172-183, 2011.

[131] K. N. Lai and S. C. W. Tang, Eds., Diabetes and the Kidney, vol. 170, Contributions to Nephrology, Karger, Basel, Switzerland, 2011.

[132] P. Zürbig, G. Jerums, P. Hovind et al., "Urinary proteomics for early diagnosis in diabetic nephropathy," Diabetes, vol. 61, no. 12, pp. 3304-3313, 2012.

[133] F. Raimondo, S. Corbetta, L. Morosi et al., "Urinary exosomes and diabetic nephropathy: a proteomic approach," Molecular BioSystems, vol. 9, no. 6, pp. 1139-1146, 2013.

[134] I. Zubiri, M. Posada-Ayala, A. Sanz-Maroto et al., "Diabetic nephropathy induces changes in the proteome of human urinary exosomes as revealed by label-free comparative analysis," Journal of Proteomics, vol. 96, pp. 92-102, 2014.

[135] A. Caseiro, A. Barros, R. Ferreira et al., "Pursuing type 1 diabetes mellitus and related complications through urinary proteomics," Translational Research, vol. 163, no. 3, pp. 188-199, 2014.

[136] B. Jim, J. Santos, F. Spath, and J. C. He, "Biomarkers of diabetic nephropathy, the present and the future," Current Diabetes Reviews, vol. 8, no. 5, pp. 317-328, 2012. 


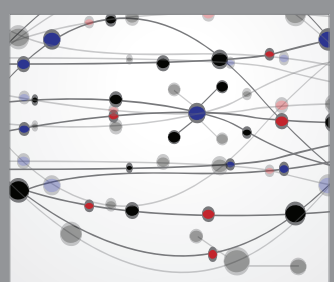

The Scientific World Journal
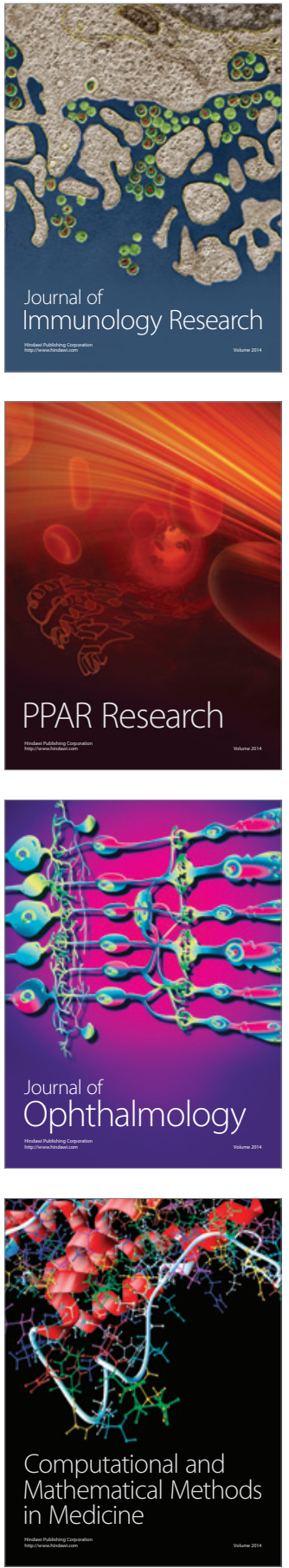

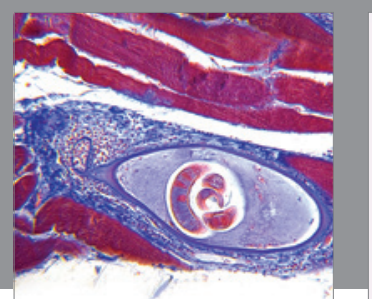

Gastroenterology Research and Practice

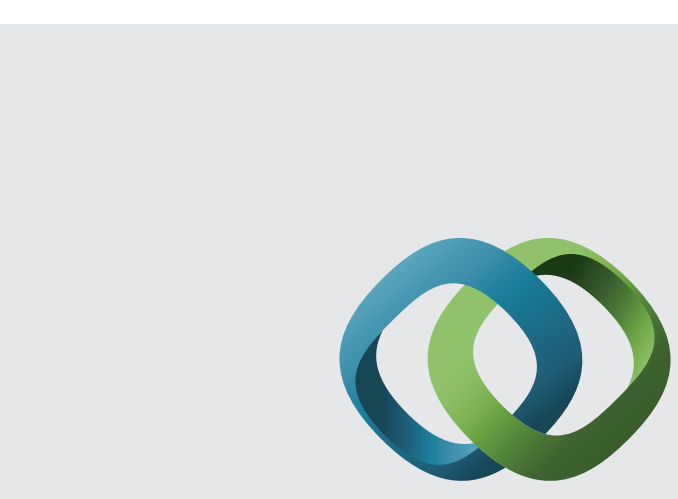

\section{Hindawi}

Submit your manuscripts at

http://www.hindawi.com
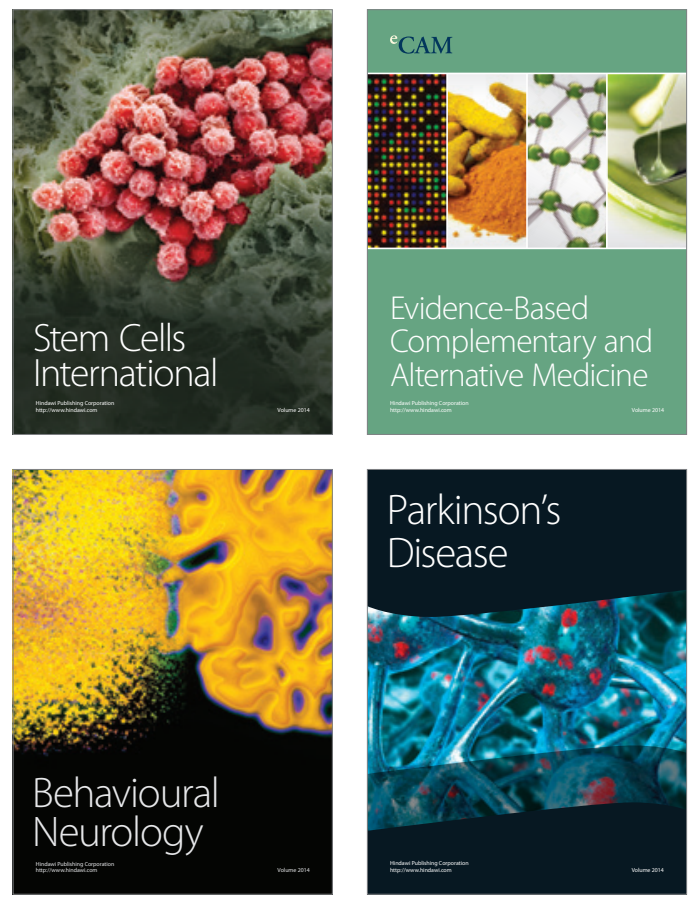
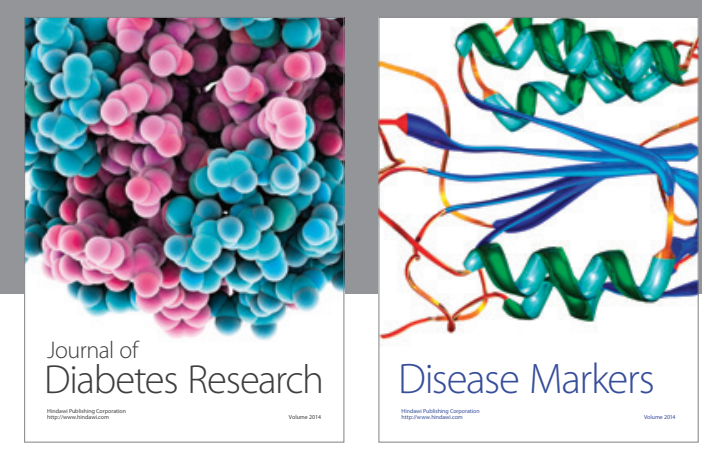

Disease Markers
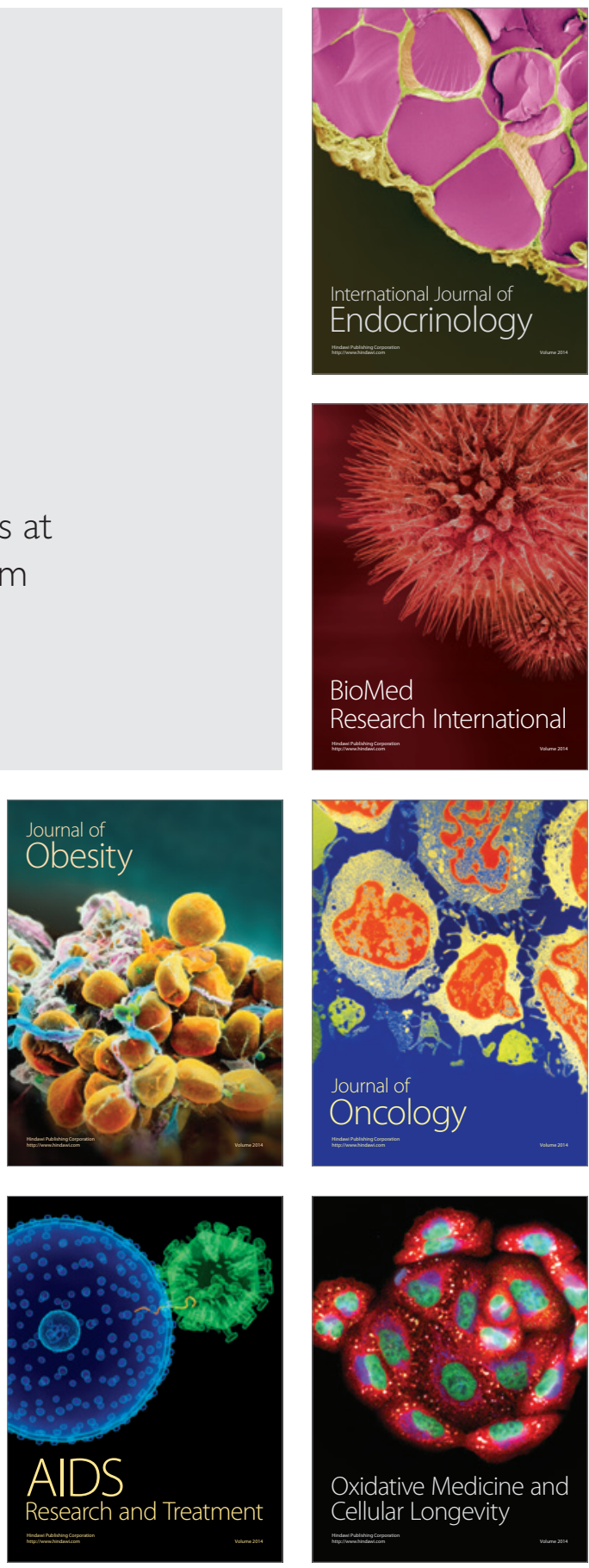